International Journal of Health Sciences
Available online at www.sciencescholar.us
Vol. 5 No. 3, December 2021, pages: 321-330
e-ISSN: 2550-696X, p-ISSN: 2550-6978
https://doi.org/10.53730/ijhs.v5n3.1529

\title{
Legal Provision for Medical Aid and Medical Service in Ukraine
}

CrossMark

\author{
Stanislav Husariev a, Tetiana Tarakhonych ${ }^{b}$, Olena Biloskurska c , Olha Starytska d, Olha Nesen e \\ Manuscript submitted: 09 May 2021, Manuscript revised: 27 August 2021, Accepted for publication: 23 September 2021
}

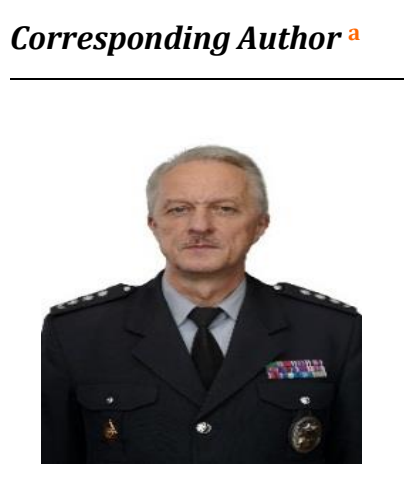

Keywords

comparison criteria; healthcare system; medical aid; medical service; primary health; Ukrainian legislation;

\begin{abstract}
In the process of any human right exercising there is always an issue related to the quality of received service or aid especially in the healthcare sector. Authors analyzed applicable legislation of Ukraine regulating the provision of medical aid and services with the use of the following methods - analysis, interpretation, hermeneutics, systemic-structural. During the research were analyzed applicable legislation which contains medical aid and service definitions and peculiarities of its regulation. According to the results of regulatory framework analysis, we can state that definitions "medical aid" and "medical service" are mutually reinforcing as medical aid comprises relevant procedures. Comparison of these phenomena also can be performed based on other criteria, namely: subjective composition (professional medical staff will always be the provider, in case of emergency cases - persons whose duty is to provide primary medical aid as part of their activity; medical services are provided by state and municipal facilities along with higher educational establishments and research centers, i.e. not only medical staff; payment (regarding the subject - free of charge or paid; services are paid per se except if covered by relevant budget category); financial guarantee (both processes are guaranteed by the state except special cases and if medical insurance program is selected).
\end{abstract}

International Journal of Health Sciences (C) 2021. This is an open access article under the CC BY-NC-ND license (https://creativecommons.org/licenses/by-nc-nd/4.0/).

\section{Contents}

Abstract

1 Introduction.

Comparison of the Concepts of "Medical Aid" and "Medical Service" in Ukrainian and International Legislation...

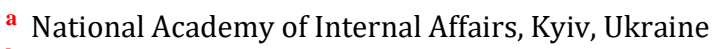

${ }^{b}$ V.M. Koretsky Institute of State and Law of the National Academy of Sciences of Ukraine, Kyiv, Ukraine

c Yuriy Fedkovych Chernivtsi National University, Chernivtsi, Ukraine

${ }^{\text {d }}$ National Academy of Internal Affairs, Kyiv, Ukraine

e National Academy of Internal Affairs, Kyiv, Ukraine
} 
3 Comparison of Legal Aid and Legal Services According to Different Criteria..

4 Conclusion

Acknowledgments..

References

\section{Introduction}

Recently due to the presentation of the broad spectrum of organizational innovations in the healthcare sector, a lot of attention has been paid to the quality of medical aid provided to citizens. Namely, healthcare reform stipulates certain transformation of primary healthcare area (establishment of family doctor component), refunding of healthcare facilities depending on its specialization and range of activities, newborn and obstetric fosterage, implementation of "Accessible treatment" program, etc. Currently, duties and obligations have already been segregated between emergency aid services and other medical facilities, the scope of competence of private healthcare facilities has been sufficiently extended, the procedure for medical preventive aid has been transformed, the electronic prescription system has been introduced (Deshko et al., 2021; Bortnik et al., 2020). All the above mentioned stimulates analysis of such definitions as "medical aid" and "medical service", correlation of its content, implementation, and enforcement subjects. It requires additional study with the aim to develop optimal ways to improve the healthcare system in general, its specific components, in particular paid services and free-of-charge aid (Fyl et al., 2020; Deshko et al., 2021).

Scientific issues of social relations legal regulation in the medical field are not new to the theoretical jurisprudence. Therefore, there are fundamental works of representatives of legal and medical science, whose role is important in addressing the institutionalization of national legislation, its compliance with trends in medicine, the effectiveness of application, etc.

In the works of Gubsky et al. (2007), Khodora et al. (2007), Zhakhovsky (2016), others, that have researched the topics about the development of law in the medical field, the emphasis has been made not only on the levels of legal regulation (international, national, legislative, bylaw), the creation of a single medical space, improving services for village residents, strengthening the material and technical base or innovative factors of legal regulation (reproduction, cloning, transplantation), features of regulation of emergency medical care for patients with COVID-19, but also on other important aspects of the development of the medical field of law as a complex formation (Kurtieva et al., 2021; Dharmayuda et al., 2021). At the same time, in characterizing the research condition of the selected phenomenon, it is necessary to pay attention to the paucity of publications that contain the normative context of terminological interpretations, including such fundamental concepts as medical aid and medical service, which caused the appeal to the selected issues (Suner, 2015; Trihastuti et al., 2020). That is why this research is aimed at the analysis of a regulatory framework for medical aid/services provision in Ukraine based on different comparison criteria (Barzilay et al., 1999; Robert et al., 2010). To reach the defined aim relevant tasks and certain methodological base must be outlined:

a) Present the regulatory content and comparison of such definitions as "medical aid" and "medical service" by studying the applicable international and domestic legislation and with methods of analysis, interpretation, and equipartition;

b) Study the available regulatory framework and characterize the criteria for medical aid and medical service segregation using classification, hermeneutics, and systemic-structural method;

c) Present conclusions using the generalization method. 


\section{Comparison of the Concepts of "Medical Aid" and "Medical Service" in Ukrainian and International Legislation}

Before we start comparing the regulatory framework and segregate the "medical aid" and "medical service" definitions it is appropriate to analyze the applicable Ukrainian and international legislation to define the correlation between definitions contained (Chima et al., 1997). Therefore, having considered many documents devoted to this issue, we can state that they do not have any definition of "medical care", but there are relevant provisions for the recognition of such a person's right For example, in part 2 (d) Article 12 of the International Covenant on Economic, Social and Cultural Rights (1966) noticed, that "the steps to be taken by the States Parties to the present Covenant to achieve the full realization of this right shall include the creation of conditions which would assure to all medical service and medical attention in the event of sickness" (Wilchesky et al., 2004; Green \& Pope, 1999).

In part 2 (b) Article 24 of the Convention on the Rights of the Child (1989) fixed that "States Parties shall take appropriate measures to ensure the provision of necessary medical assistance and health care to all children with an emphasis on the development of primary health care". Also, part 1 (13) of the European Social Charter (1961) guarantied, that "anyone without adequate resources has the right to social and medical assistance" and in Article 13 of this Convention appropriate security measures are provided.

It is worth focusing on the provisions of the European Convention on Social and Medical Assistance and its Protocol (ETS No. 14) (1953), which contain provisions on cooperation between the member states of the Council of Europe in various fields, including medical aid. In such definition, it is proposed to understand "to each Contracting Party all assistance granted under the laws and regulations in force in any part of its territory under which persons without sufficient resources are granted means of subsistence and the care necessitated by their condition, other than non-contributory pensions and benefits paid in respect of war injuries due to foreign occupation". However, the peculiarity of this document is that it extends only to the states of the Council of Europe.

As for the international definition of the term "medical service", in the process of our scientific research, we found only one international legal act that would contain provisions for the definition of this concept. According to Article 1 of the Medical Care and Sickness Benefits Convention (No. 130) (1969) the term medical service "includes allied benefits". At the same time, it seems rather unclear what is meant by this definition, as the article itself contains only an indication of the legislation and persons who may receive such services (husband, wife, children under 14 years and older). According to the national legal analyzed documents, the normative interpretation of the term "aid" contained exclusively in three international instruments ratified by Ukraine, namely:

a) Means either direct benefit in the form of care or indirect benefit consisting of reimbursement of the expenses borne by the person concerned (Social Security..., 1952);

b) Means any measure fulfilling the criteria laid down in Article 107(1) of the Treaty (part 1, 1.3 (b) Communication from the commission (2014);

c) About each Contracting Party all assistance granted under the laws and regulations in force in any part of its territory under which persons without sufficient resources are granted means of subsistence and the care necessitated by their condition, other than non-contributory pensions and benefits paid in respect of war injuries due to foreign occupation" (European Convention..., 1953).

At the level of national legislation, we reviewed the normative definition of the term "service" and have identified seventeen definitions of "service" and more than eighty that are directly related to the scope. We consider the most extensive definitions used by the legislator as specific juridical constructions in the system of rules of legal technique. So, judicial constructions allow fixing service as:

a) The activity of the executor on granting (transfer) to the consumer of a certain material or intangible good determined by the contract, which is carried out by individual order of the consumer to meet his personal needs (The Law of Ukraine "On Consumer Protection", 1991);

Husariev, S., Tarakhonych, T., Biloskurska, O., Starytska, O., \& Nesen, O. (2021). Legal provision for medical aid and medical service in Ukraine. International Journal of Health Sciences, 5(3), 321-330. https://doi.org/10.53730/ijhs.v5n3.1529 
b) reception and service of insured persons, persons registered with the Pension Fund as recipients of pensions, persons entitled to a pension, payment of funeral allowances, insurers or their authorized persons to resolve the issue with which they apply to the Pension Fund authorities (The Resolution of the Board of the Pension Fund..., 2015);

c) administrative service provided to an individual (The Order of the Ministry of Internal Affairs..., 2018);

d) action to provide information (data) and/or documents in electronic form (The Order of the Ministry of Finance..., 2017);

e) service of production nature of third-party organizations for maintenance and operation of production equipment and equipment used in the technological process of design development, production of security paper, banknotes, coins and state awards of Ukraine, their storage, transportation and accounting, research or consulting, including new technologies, protection systems, examinations, assessments, preparation of conclusions, as well as training of employees, etc. (The Resolution of the Board of the National Bank..., 2013);

f) any subject of purchase, except for goods and works, in particular transport services, development of technologies, scientific researches, research or development, medical and household services, hire (rent), and also financial and consulting services, current repairs (The Law of Ukraine "On Public Procurement"..., 2015).

As for the direct subject of research, which is limited to the medical field, in Ukrainian domestic legislation, few acts are containing the definition of medical aid. Firstly the Resolution of the Cabinet of Ministers of Ukraine No. 955 "On approval of the Program for state-guaranteed free medical aid provision to citizens" (2002) where it is clearly stated that "medical aid is a type of activity which comprises a set of measures aimed at patients' treatment and health improvement if their condition poses threat to life, health, and working ability and must be performed by professionally trained employees with relevant authority and capacity according to legislation".

Secondly, we should analyze the Order of Foreign Intelligence Service of Ukraine No. 246 "Approval of Instruction on the organization of medical aid provision in Foreign Intelligence Service of Ukraine" (2014) where it is clearly stated that "medical aid is the activity of professionally trained medical employees aimed at prevention, diagnostics, treatment and rehabilitation in certain conditions caused by disease, traumas, intoxications, and pathoses along with pregnancy and labor". Identical definition is contained in the Law of Ukraine "Basic laws of Ukraine regulating healthcare activities" No. 2801-XII (1992).

Having compared the content of both definitions we may conclude that the Order of Foreign Intelligence Service of Ukraine (2014) and Law of Ukraine "Basic laws of Ukraine regulating healthcare activities" (1992) present more detailed interpretations whereas the Resolution of the Cabinet of Ministers of Ukraine "On approval of the Program for state-guaranteed free medical aid provision to citizens" (2002) does not mention prevention and rehabilitation procedures, the definition itself is more constrained in terms of content and temporal limitations (aid is to be provided directly to the person if the critical condition is established). Also, there is a subtle controversy related to the definition of the service provider (subject) as "...professionally trained employees with relevant authority and capacity according to legislation" must not necessarily be doctors but, for example, policemen (The Law of Ukraine “On National Police of Ukraine”, 2015). It is doubtful if this person can professionally perform any activities related to health improvement or treatment, especially long-term. These employees will be able to provide emergency medical aid to sustain life and health before medics' arrival, create certain conditions for further recovery (Schubert et al., 2016).

Domestic legislation contains only one definition of "medical service" - Law of Ukraine "Basic laws of Ukraine regulating healthcare activities" states that "medical service is a service provided to the patient by a healthcare facility or individual entrepreneur registered according to established procedure with the issuance of a license for business activity performance involving medical practice and paid by the requestor (Tripathi et al., 2020; Widana et al., 2021). Therefore, comparing with the definition of "medical aid", this does not mention such characteristics as:

a) Professionalism;

b) Qualification;

c) List of services and cases for its provision which are essential. 


\section{Comparison of Legal Aid and Legal Services According to Different Criteria}

Turning to a more detailed understanding of the legal regulation of medical care in Ukraine, in our opinion, it is worth paying attention to such its (legal regulation) components as: content, subject composition, availability of payment, and guarantee. Therefore, when interpreting medical care according to the criterion of content, we observe that the legislator refers to the list of types of medical care such as:

a) Emergency (medical aid of urgent nature comprising a set of emergency organizational, diagnostic measures and treatment to save and sustain life and health in critical condition and minimize the consequences of its impact) (The Law of Ukraine "On Emergency Medical Aid", 2012);

b) Primary (dynamic monitoring of patient's condition; diagnostics and treatment of the most widespread diseases, injuries, intoxications, pathological and physiological (pregnancy) conditions; provision of emergency medical aid in case of physical/mental disorders to patients in the scope of PHC; referrals based on patients' medical indications (if no emergency aid is required) for provision of secondary (specialized) or tertiary (highly specialized) medical aid; interaction with providers of secondary (specialized) or tertiary (highly specialized) medical aid; required medical interventions in case of identification of factors of certain disease development; preventive interaction (vaccination, notifications on infectious diseases, epidemiological examination of individual cases of infectious diseases); advisory support; dynamic monitoring of uncomplicated pregnancy; monitoring of healthy children; specific services related to palliative aid (patients of all ages and referrals for provision of palliative aid beyond the PHC scope); prescription of pharmaceuticals and medical products, technical rehabilitation means and other organizational services) (The Order of Ministry of Healthcare of Ukraine No. 504..., 2018);

c) Specialized (aid provided in both formats - in-patient and put-patient - by doctors with required specialization (except family doctors), scheduled and urgent, with consultations, diagnostics, treatment, rehabilitation and prevention of diseases, injuries, intoxications, pathological and physiological (pregnancy/delivery) conditions; referrals based on patients' medical indications for provision of secondary (other specialists) or tertiary (highly specialized) medical aid) (The Law of Ukraine "Basic laws of Ukraine..., 1992);

d) Highly specialized (aid provided in both formats - in-patient and put-patient, scheduled and urgent, with consultations, diagnostics, treatment, rehabilitation and prevention of diseases, injuries, intoxications, pathological and physiological (pregnancy/delivery) conditions with use o highly specialized equipment and/or relevant complex of medical procedures; referrals based on patients' medical indications for provision of secondary (specialized) or tertiary (highly specialized) medical aid (The Law of Ukraine "Basic laws of Ukraine..., 1992);

e) Palliative (set of measures aimed at improvement of patient's and his/her relatives' life quality, prevention, and minimization of patient's suffering (emotional and physical) with early diagnostics of pain symptoms and certain disorders, the performance of appropriate medical activities, symptomatic therapy, and aid, psychological, social, spiritual support or rehabilitation regardless of patient's age, condition, social status, nationality, religious/political beliefs, place of residence) (The Order of Ministry of Healthcare of Ukraine No. 733..., 2018).

Resolution of the Cabinet of Ministers of Ukraine "On approval of the list of paid services provided in public and municipal health institutions and higher medical institutions" (1996) will be a good foundation for further study of the problem - it establishes the list of paid medical services differentiated by the legislator based on content. For example, some of its provisions state that state and municipal healthcare facilities provide the following paid services: cosmetological; anonymous testing and treatment of persons with STDs and different types of addiction (except HIV/AIDS testing); infertility treatment and abortion (various medical indications); physical health improvement and prevention; consultations and treatment of articulation disorders; medical examinations; dentist's and ophthalmologist's services; management of recreational facilities, sport competitions, cultural and social events; laboratory testing; provision of aid to patients (in-patient and outpatient) including separate agreement conclusion; preventive vaccination for different categories; services

Husariev, S., Tarakhonych, T., Biloskurska, O., Starytska, O., \& Nesen, O. (2021). Legal provision for medical aid and medical service in Ukraine. International Journal of Health Sciences, 5(3), 321-330.

https://doi.org/10.53730/ijhs.v5n3.1529 
involving telemedicine and nonconventional medicine; different types of forensic examination; examination, consulting and treatment of patients with sexual disorders except cases involving complex mental problems; management and issuance of relevant records; radiopharmaceuticals and donor's blood; training of nonmedical staff (emergency aid) and doctors' (pharmacists) internship; clinical trials of drugs and research; medical services provided by research facilities of National Academy of Medical Sciences; tertiary medical aid (transplantation of organs).

Upon the results of the comparison, we would like to present certain critical remarks to the presentation of material in legislative acts. In particular, at first glance, it seems that list of medical aid formats is radically different from the list of medical services but it is not so. Legislator uses the category "medical aid" to cover separate services which are its components. Regarding this, there is a necessity to compare the content of definitions, the performance of additional interpretation. For example, the Law of Ukraine "Basic laws of Ukraine regulating healthcare activities" (1992) stipulates the provision of specialized medical aid as its separate type including consultations and diagnostics. Decree of the Cabinet of Ministers of Ukraine "On approval of the list of paid services provided by state and municipal healthcare facilities and higher educational establishments" (1996) mentions identical types of medical service - diagnostics, prevention, treatment, consulting, etc (McCarthy et al., 2020; Matsumoto et al., 2010).

The definitions are also compared based on service/aid providers (subjects). After analyzing the lists of The Law of Ukraine "On Emergency Medical Aid" (2012), we can state that medical aid is provided by professional medical staff, emergency service staff, fire brigade members, policemen, pharmacists, carriage stewards, airplanes crew, and persons with relevant duties. Still, medical services may be provided by a healthcare facility or individual entrepreneur who is registered and granted a license to perform business activity related to medical practice - state and municipal healthcare facilities, higher educational establishments and research centers, private legal entities acting on a paid basis (Dusnaevich, 2020).

One of the urgent issues is the receiver of service/aid - the patient. Applicable legislation guarantees that medical aid is provided to citizens of Ukraine, stateless persons residing permanently within the territory of Ukraine, persons officially recognized as refugees or requiring special protection, and covered by the state budget (The Resolution of the Cabinet..., 2015). Foreigners and stateless persons residing temporarily within the territory of Ukraine must pay for aid/services - after receiving emergency aid they individually cover expenses on treatment and health improvement. Medical services requestor may be presented by state, local governance bodies, legal entities, and individuals including patients.

According to the analysis of the abovementioned legislative acts, the following criterion is payment. The legislation states that medical aid is provided to citizens of Ukraine, persons residing permanently within the territory of Ukraine free of charge except persons residing temporarily within the territory of Ukraine (Ho \& Casey, 1998; Yoo et al., 2016). Medical services are provided on a paid basis except for cases when the state guarantees coverage from the budget for special services. Of the same significance is the criterion of financial guarantee - the Law of Ukraine "On financial guarantees of medical aid" states that "medical guarantee program is approved by Verkhovna Rada of Ukraine and included in the state budget". Therefore, every year state establishes the list of certain activity categories (both medical aid and medical services) covered from the budget. If the person wants to receive medical aid or services which cost is not covered, one may pay individually or reimburse the cost with the use of medical insurance.

\section{Conclusions}

Therefore, based on analysis of applicable domestic legislation we may state that Ukraine guarantees the provision of both medical aid and services which are different legal categories. After comparison with the use of different criteria, we identified that medical aid and services are mutually reinforcing when it comes to content - the latter may be the component of the former phenomenon.

We chose subjective composition to be another criterion of comparison - medical aid may be provided by professional staff and persons with a certain duty to provide emergency aid as part of their activity. In contrast to that, medical services are provided by state and municipal healthcare facilities including higher educational establishments and individual entrepreneurs with a relevant license for medical practice. 
The patient will always be the receiver of relevant services - a more detailed analysis of patients' classification shows that one more criterion must be considered while comparing medical aid and services payment. Permanent residents get medical aid free of charge while persons who temporarily stay within the territory of Ukraine have to pay for it. Also, medical service is provided for each person at a cost except for cases when the state is the requestor and a certain amount is allocated in the budget (exclusively for permanent residents). The following criterion thus is the financial guarantee in the format of state support for the provision of medical service/aid which may be individually ensured (independent payment or compensation through medical insurance system).

\section{Acknowledgments}

We are grateful to two anonymous reviewers for their valuable comments on the earlier version of this paper.

Husariev, S., Tarakhonych, T., Biloskurska, O., Starytska, O., \& Nesen, O. (2021). Legal provision for medical aid and medical service in Ukraine. International Journal of Health Sciences, 5(3), 321-330. https://doi.org/10.53730/ijhs.v5n3.1529 


\section{References}

Barzilay, J. I., Spiekerman, C. F., Wahl, P. W., Kuller, L. H., Cushman, M., Furberg, C. D., ... \& Savage, P. J. (1999). Cardiovascular disease in older adults with glucose disorders: comparison of American Diabetes Association criteria for diabetes mellitus with WHO criteria. The Lancet, 354(9179), 622-625. https://doi.org/10.1016/S0140-6736(98)12030-5

Bortnik, S., Kalenichenko, L., \& Slynko, D. (2020). Separate Aspects Of Legal Responsibility Of Medical Workers On The Example Of Ukraine, Germany, France, The USA. Georgian Medical News, (306), 171-178.

Chima, C. S., Barco, K., Dewitt, M. L., Maeda, M., Teran, J. C., \& Mullen, K. D. (1997). Relationship of nutritional status to length of stay, hospital costs, and discharge status of patients hospitalized in the medicine service. Journal of the American Dietetic Association, 97(9), 975-978. https://doi.org/10.1016/S00028223(97)00235-6

Deshko, L., Vasylchenko, O., Sherbak, I., Galai, V., \& Medvid, A. (2021). Ukraine's International Liabilities On Initiation Of Measures For Public Health Protection And The Role Of Local Authorities In Implementation Of Health Care Policy. Georgian Medical News, (312), 163-168.

Dharmayuda, T. G., Suega, K., Bakta, I. M., \& Sumohadi, I. M. D. (2021). Ki67 expression and prognostic aspects of colorectal cancer. International Journal of Health Sciences, 5(2), 79-88.

Dusnaevich, R. U. (2020). The need and methods for the state regulation of private medical services in the conditions of the COVID-19 pandemic. International Journal of Current Research and Review, 112-116.

Fyl, S., Kulyk, O., Fedotova, H., Lelet, S., \& Vashchuk, N. (2020). Medical Malpractice And Legal Liability In The Rendering Of Healthcare Services In Ukraine. Georgian Medical News, (306), 178-183.

Green, C. A., \& Pope, C. R. (1999). Gender, psychosocial factors and the use of medical services: a longitudinal analysis. Social science \& medicine, 48(10), 1363-1372. https://doi.org/10.1016/S0277-9536(98)00440-7

Gubsky, Y., Serduyk, V., Tsarenko, A., Yakymenko, O., Skripnik, O., Solopa, L., Konovalenko, O., \& Vinnytska, M. (2007). Legal regulation of medical care in Ukraine. Medical law of Ukraine: problems of formation and development. First All-Ukrainian scientific-practical conference, 105-112.

Ho, J., \& Casey, B. (1998). Time saved with use of emergency warning lights and sirens during response to requests for emergency medical aid in an urban environment. Annals of emergency medicine, 32(5), 585588. https://doi.org/10.1016/S0196-0644(98)70037-X

Khodora, O., Parobetska, I., \& Hrynash, V. (2007). Legal regulation of medical care granting in Ukraine.

Kurtieva, S., Nazarova, J., \& Mullajonov, H. (2021). Features of endocrine and immune status in adolescents with vegetative dystonia syndrome. International Journal of Health Sciences, 5(2), 118-127.

Matsumoto, M., Inoue, K., Bowman, R., Noguchi, S., Toyokawa, S., \& Kajii, E. (2010). Geographical distributions of physicians in Japan and US: Impact of healthcare system on physician dispersal pattern. Health Policy, 96(3), 255-261. https://doi.org/10.1016/j.healthpol.2010.02.012

McCarthy, C. P., Murphy, S., Jones-O'Connor, M., Olshan, D. S., Khambhati, J. R., Rehman, S., ... \& Wasfy, J. H. (2020). Early clinical and sociodemographic experience with patients hospitalized with COVID-19 at a $\begin{array}{lll}\text { large American } & \text { healthcare } & \text { system. EClinicalMedicine, 26, }\end{array}$ https://doi.org/10.1016/j.eclinm.2020.100504

Robert, A. M., Kramer, R. S., Dacey, L. J., Charlesworth, D. C., Leavitt, B. J., Helm, R. E., ... \& Northern New England Cardiovascular Disease Study Group. (2010). Cardiac surgery-associated acute kidney injury: a comparison of two consensus criteria. The Annals of thoracic surgery, 90(6), 1939-1943. https://doi.org/10.1016/j.athoracsur.2010.08.018

Schubert, M., Schian, M., \& Viehmeier, S. (2016). The federal participation law: New requirements for needs assessment with special emphasis on medical rehabilitation services. Bundesgesundheitsblatt, Gesundheitsforschung, Gesundheitsschutz, 59(9), 1053-1059.

Suner, S. (2015). Assessing and planning health actions during a crisis. Turkish journal of emergency medicine, 15, 8-10. https://doi.org/10.5505/1304.7361.2015.59365

Trihastuti, N., Putri, S., \& Widjanarko, B. (2020). The impact of asymmetric information in medical services: A study in progressive law.

Tripathi, G., Ahad, M. A., \& Paiva, S. (2020, March). S2HS-A blockchain based approach for smart healthcare system. In Healthcare (Vol. 8, No. 1, p. 100391). Elsevier. https://doi.org/10.1016/j.hjdsi.2019.100391 
Widana, I.K., Sumetri, N.W., Sutapa, I.K., Suryasa, W. (2021). Anthropometric measures for better cardiovascular and musculoskeletal health. Computer Applications in Engineering Education, 29(3), 550561. https://doi.org/10.1002/cae.22202

Wilchesky, M., Tamblyn, R. M., \& Huang, A. (2004). Validation of diagnostic codes within medical services claims. Journal of clinical epidemiology, 57(2), 131-141. https://doi.org/10.1016/S0895-4356(03)00246-4

Yoo, K. B., Ahn, H. U., Park, E. C., Kim, T. H., Kim, S. J., Kwon, J. A., \& Lee, S. G. (2016). Impact of co-payment for outpatient utilization among Medical Aid beneficiaries in Korea: A 5-year time series study. Health Policy, 120(8), 960-966. https://doi.org/10.1016/j.healthpol.2016.07.001

Zhakhovsky, V., Livinský, V. (2016). The concept of reform and development of the medical support system of the Armed Forces of Ukraine: opinion on the formation and implementation. Modern Aspects of Military Medicine, 23, 13-29.

Husariev, S., Tarakhonych, T., Biloskurska, O., Starytska, O., \& Nesen, O. (2021). Legal provision for medical aid and medical service in Ukraine. International Journal of Health Sciences, 5(3), 321-330. https://doi.org/10.53730/ijhs.v5n3.1529 


\section{Biography of Authors}

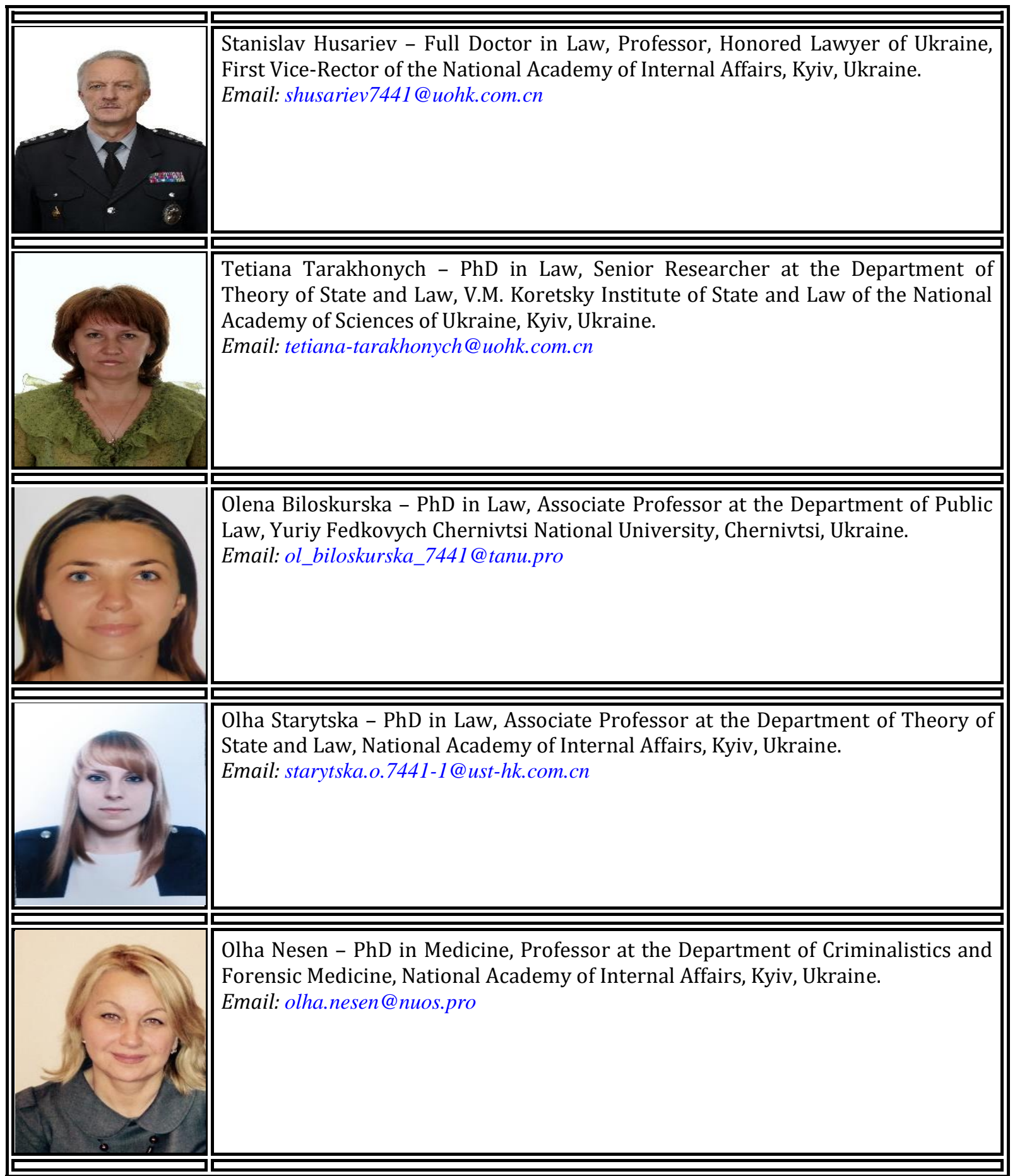

